\title{
MicroRNA expression profiles of cancer stem cells in head and neck squamous cell carcinoma
}

\author{
KAZUYA YATA $^{1}$, LEVENT BEKIR BEDER ${ }^{1}$, SHUNJI TAMAGAWA ${ }^{1}$, MUNEKI HOTOMI ${ }^{1}$, \\ YOSHIHIKO HIROHASHI ${ }^{2}$, REIDAR GRENMAN ${ }^{3}$ and NOBORU YAMANAKA ${ }^{1}$ \\ ${ }^{1}$ Department of Otolaryngology-Head and Neck Surgery, Wakayama Medical University, Wakayama 641-8509; \\ ${ }^{2}$ Department of Pathology, Sapporo Medical University School of Medicine, Chuo-Ku, Sapporo, Japan; \\ ${ }^{3}$ Department of Otorhinolaryngology-Head and Neck Surgery and Department of Medical Biochemistry, \\ Turku University Hospital, University of Turku, Turku, Finland
}

Received June 22, 2015; Accepted August 10, 2015

DOI: $10.3892 /$ ijo.2015.3145

\begin{abstract}
Increasing evidence indicates that cancer stem cells have essential roles in tumor initiation, progression, metastasis and resistance to chemo-radiation. Recent research has pointed out biological importance of microRNAs in cancer stem cell dysregulation. Total number of mature microRNAs in human genome increased to more than 2,500 with the recent up-date of the database. However, currently no information is available regarding microRNA expression profiles of cancer stem cells in head and neck squamous cell carcinoma (HNSCC). Increased ALDH1 activity has been demonstrated as a reliable marker for isolation of cancer stem cells. Therefore, we evaluated the microRNA expression profile of ALDH1-high subpopulations in the HNSCC cell lines UTSCC-9 and UTSCC-90. Initially, we examined cancer stem cell properties of ALDH1-high subpopulations in both cell lines. We analyzed expression of stemness markers, sphere formation capacity and xenograft transplantation into NOD/SCID mice. Our findings validated that ALDH1-high subpopulations showed significantly increased tumor-initiating ability. Furthermore, we investigated the microRNA expression profile of HNSCC stem cells using microRNA array and confirmed the results by quantitative real-time PCR. We found that expressions of miR-424, let-7a, miR-6836, miR-6873 and miR-7152 were downregulated, whereas miR-147b was upregulated with statistical significance in the ALDH1-high subpopulation. In conclusion, we identified a subset of microRNAs that were differentially expressed in ALDH1-high subpopulation, providing new microRNA targets to study dysregulation of
\end{abstract}

Correspondence to: Professor Noboru Yamanaka, Department of Otolaryngology-Head and Neck Surgery, Wakayama Medical University, Kimiidera 811-1, Wakayama-shi 641-0012, Wakayama, Japan

E-mail: ynobi@wakayama-med.ac.jp

Key words: head and neck cancer, microRNA, microarray, cancer stem cells, cell line
HNSCC-initiating cells and develop therapeutic strategies aimed at eradicating the tumorigenic stem cells in HNSCC.

\section{Introduction}

Head and neck squamous cell carcinoma (HNSCC) originates from mucosal epithelial lining of the upper aerodigestive tract. The incidence of the disease has gradually increased over the last three decades, especially associated with HPV infection (1). A typical case presents at an advanced stage as a metastatic cancer, which accounts for the poor mortality rate. Despite the progress in methodology and clinical efficacy of radiotherapy, chemotherapy and surgical approaches up to $50 \%$ of patients who die from HNSCC have local or regional recurrence (2). Detailed molecular characterization of HNSCC tumors might help to identify subpopulations for appropriate therapeutic modalities and lead to improvement of the prognosis.

Evidence from xenotransplantation studies revealed that only a small subpopulation in cancer cells has the driving force of cancer growth. Those cells responsible for tumor initiation, carcinogenesis, progression, and metastasis defined to be tumor-initiating cells or cancer stem cells (CSC) (3). In addition, CSCs also possess significant resistance to chemotherapy and radiotherapy $(4,5)$. CSCs have been isolated in several types of epithelial cancers including HNSCC (6). Thus, studies on CSCs may provide clues for improvement of prognosis associated with development of metastases and therapy-resistant local and regional recurrences in HNSCC.

There are a number of methods for isolating and characterizing cancer stem cells, mostly based on fluorescence-activated cell sorting (FACS). Expression of cell surface markers such as CD44, CD133 or drug-detoxifying surface transporter proteins has been used commonly in CSC isolation. However, xenotransplantation study is the gold standard for verification of CSC property, as tumor initiation ability of the isolated cells is evaluated in NOD/SCID mice through serial dilutions (7). Moreover, Aldefluor assay has been developed to isolate CSCs based on aldehyde dehydrogenase 1 (ALDH1) activity (8). Although all these methods were also validated in HNSCC, 
Aldefluor assay has been found to show higher sensitivity in isolation of CSCs as compared to the expression of cell surface marker, CD44 $(9,10)$.

MicroRNAs (miRNAs) are small non-protein coding RNA molecules, which act to regulate gene expression by post-transcriptional interactions with mRNA. miRNAs are assumed to regulate more than one-third of all genes related with various physiological and pathological processes including carcinogenesis (11). In our previous study, we showed the role of miRNA-200 family in epithelial-mesenchymal-transition, migration and invasion ability of HNSCC (12). Moreover, recent research has indicated the biological importance of miRNAs in CSC dysregulation (13).

In human genome, so far $>2,500$ mature miRNAs are described according to latest release of miRNA database, miRBase 21 (14). However, currently no data exist concerning miRNA expression profiles of cancer stem cells in HNSCC. Thus, the identification of cancer stem cell-related miRNAs would provide valuable information for a better understanding of cancer stem cell properties and the molecular pathways of oncogenesis.

In the present study, we isolated a subpopulation of HNSCC cells with increased ALDH1 activity and verified their CSC properties in vitro and in vivo conditions. Moreover, we performed microRNA profile analysis to further explore the characteristics and to uncover microRNAs that may serve as novel therapeutic targets in HNSCC.

\section{Materials and methods}

Ethics statement. Experimental mice were maintained in accordance with the guidelines, and approval of the Institutional Animal Care and Use Committee of Wakayama Medical University (permit number: 672). Any animal found unhealthy or sick were promptly euthanized.

Cell lines and cultures. UTSCC-9 and UTSCC-90 cell lines $(15,16)$ were kindly provided by Dr R. Grenman (Department of Otolaryngology, Turku University, Finland). UTSCC cells were grown in RPMI-1640 medium supplemented with $10 \%$ fetal bovine serum, $1 \%$ penicillin/streptomycin and $1 \mu \mathrm{l} / \mathrm{ml}$ amphotericin B (Gibco ${ }^{\mathrm{TM}}$, Invitrogen, Japan), and all cell lines were cultured in a humidified incubator with $5 \% \mathrm{CO}_{2}$ at $37^{\circ} \mathrm{C}$. UTSCC-9 and UTSCC-90 cell lines were established from squamous cell carcinoma of laryngeal carcinoma and tongue carcinoma, respectively.

Aldefluor assay and fluorescence-activated cell sorting (FACS). We used an Aldefluor assay kit (Stem Cell Technologies ${ }^{\mathrm{TM}}$, Vancouver, Canada) to determine ALDH1 activity of cells according to the manufacturer's protocol. Cells were suspended in Aldefluor assay buffer containing $1 \mu \mathrm{mol} / 1$ per $1 \times 10^{6}$ cells of the ALDH substrate, boron-dipyrrometheneaminoacetaldehyde (BAAA), and incubated for $45 \mathrm{~min}$ at $37^{\circ} \mathrm{C}$. Each sample was treated with $45 \mathrm{mmol} / 1$ of an ALDH-specific inhibitor, diethylaminobenzaldehyde (DEAB), as a negative control. Stained cells were analyzed by BD FACSAria I ${ }^{\mathrm{TM}}$ (BD Biosciences, San Jose, CA, USA). Cells were stained with $1 \mu \mathrm{g} / \mathrm{ml}$ of propidium iodide to evaluate their viability prior to analysis. The brightly fluorescent ALDH1-expressing cells
$\left(\mathrm{ALDH} 1^{\text {high }}\right)$ were detected in the green fluorescence channel $(520-540 \mathrm{~nm})$.

Xenograft transplantation. ALDH $1^{\text {high }}$ and ALDH $1^{\text {low }}$ cells were isolated by FACS and resuspended at $5.0 \times 10^{3}$ cells in $100 \mu \mathrm{l}$ PBS and Matrigel (BD Biosciences) mixture (1:1). Then each mixture was injected subcutaneously into the right/left middle back areas of 6-week-old female non-obese diabetic/severe combined immune-deficiency (NOD/SCID) mice (NOD/ShiJic-scid Jcl, Clea-Japan, Tokyo, Japan) under inhalation anesthesia by isoflurane. Tumor initiation and progression were observed weekly and external tumor volume was calculated as $0.5 \times$ Dmax $x(D m i n)^{2}\left[\mathrm{~mm}^{3}\right]$ (Dmax:long axis, Dmin:short axis of mass).

Sphere formation assay. ALDH $1^{\text {high }}$ and ALDH1 $1^{\text {low }}$ cells were isolated by FACS and then cultured in 6-well ultra-low attachment surface dishes (Corning, Tewksbury, MA, USA) at 5,000 cells per well. The cells were cultured in stem-cell medium, serum-free DMEM/F12 (Life Technologies) supplemented with N-2 supplement (Life Technologies), $10 \mathrm{ng} / \mathrm{ml}$ recombinant human epithelial growth factor (R\&D Systems, Minneapolis, MN, USA), $10 \mathrm{ng} / \mathrm{ml}$ human basic fibroblast growth factor (R\&D Systems). Morphological change was observed daily under a light microscope for 28 days. Round cell clusters $>100 \mu \mathrm{m}$ were judged as spheres.

$m R N A$ processing and quantitative real-time PCR. Preparation of cDNA from mRNA was performed directly from cultured cell lysate using the TaqMan ${ }^{\circledR}$ Gene Expression Cells-to-CT ${ }^{\mathrm{TM}}$ kit (Ambion, Japan), according to the manufacturer's instructions. Cell lysate were reverse transcribed to cDNA using the Reverse Transcription (RT) Enzyme Mix and appropriate RT buffer (Ambion). Finally the cDNA was amplified by quantitative real-time PCR (qRT-PCR) using the included TaqMan Gene Expression Master Mix and the specific TaqMan primer/ probe assay designed for the investigated genes: ALDHIAl (Hs00946916_m1), NANOG (Hs02387400_g1), OCT4 (Hs03005111_g1), SOX2 (Hs01053049_s1) and GAPDH (Hs99999905_m1), (Applied Biosystems, Tokyo, Japan).

The gene expression levels were normalized to the expression of the housekeeping gene GAPDH and were expressed as fold changes relative to the expression of the untreated cells. The amplification profile was initiated by 10 -min incubation at $95^{\circ} \mathrm{C}$, followed by two-step amplification of $15 \mathrm{sec}$ at $95^{\circ} \mathrm{C}$ and $60 \mathrm{sec}$ at $60^{\circ} \mathrm{C}$ for 40 cycles. All experiments were performed including non-template controls to exclude contamination of the reagents. Quantification was done with the delta/delta $\mathrm{Ct}$ calculation method (17). Each sample was analyzed in triplicate on the 7500 Real-Time PCR system in a 96-well plate (Applied Biosystems).

MicroRNA processing and $q R T-P C R$. Preparation of cDNA from microRNA was also performed directly from cultured cell lysate using the TaqMan ${ }^{\circledR}$ MicroRNA Cells-to-CT ${ }^{\mathrm{TM}}$ kits (Ambion) according to the manufacturer's instructions. Cell lysate was reverse transcribed to cDNA using the RT Enzyme Mix, RT buffer and appropriate RT primer (Applied Biosystems). Finally the cDNA of each mature microRNA was amplified separately by qRT-PCR using the TaqMan 


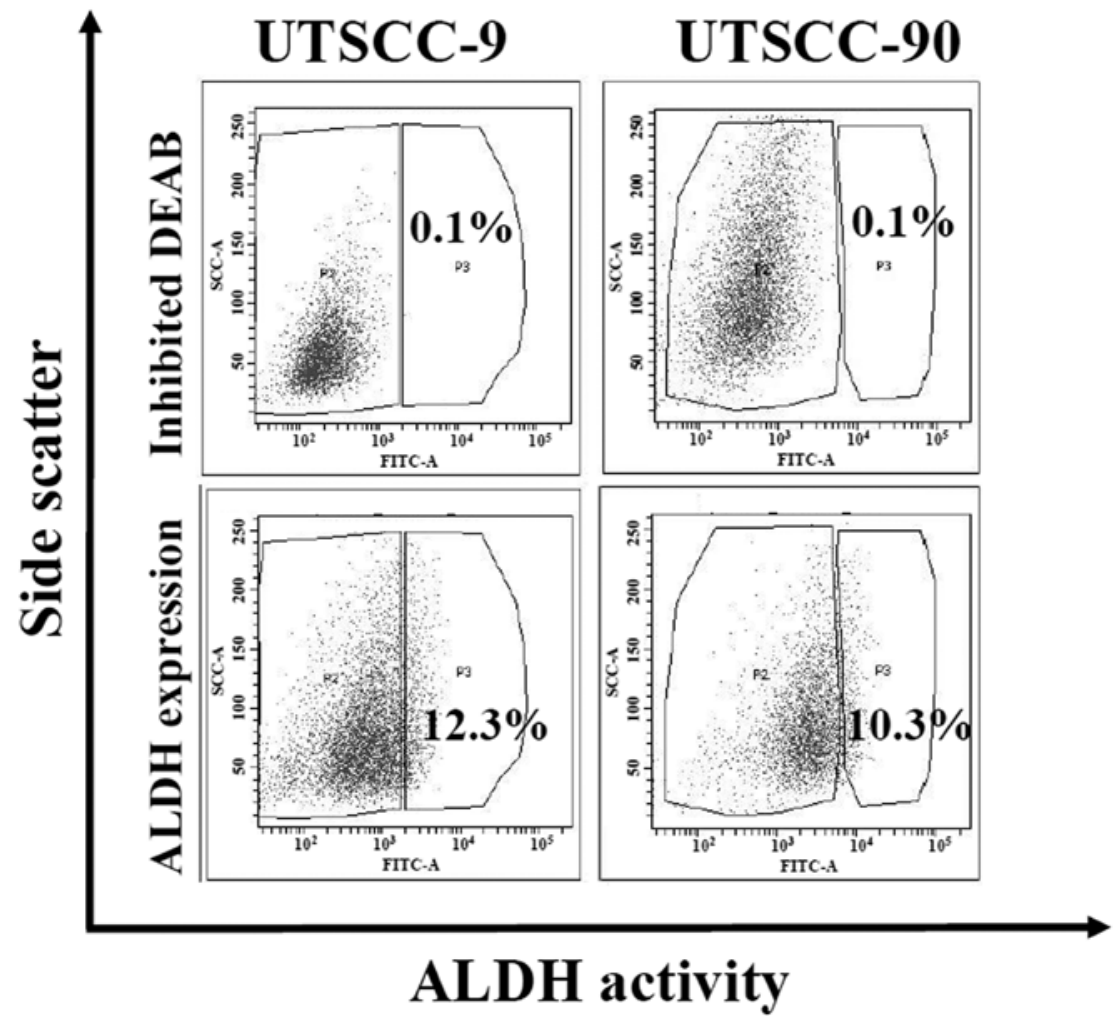

Figure 1. Isolation of ALDH1 ${ }^{\text {high }}$ cells from HNSCC cell lines. ALDH activity of two human HNSCC cell lines (UTSCC-9 and UTSCC-90) was analyzed by Aldefluor assay. Proportion of ALDH1 ${ }^{\text {high }}$ cells was isolated using FACS Aria I.

Universal Master Mix and the specific primer and probe mix included in predesigned TaqMan MicroRNA assays: hsa-miR-424; ID: 000604, hsa-miR-4730; ID: 462061_mat, hsa-miR-6836-5p; ID: 467207_mat, hsa-miR-6873-5p; ID: 467097_mat, hsa-miR-7152-3; ID: 466958_mat, hsa-hsa-let-7a; ID: 000377, hsa-miR-147b; ID: 002262, hsa-miR-3622a-3p; ID: 464955_mat, hsa-miR- miR-1976; ID: 121207_mat (Applied Biosystems). Calculation of microRNA expression was performed with the same method as described above and for normalization RNU6B RNA (RNU6B; ID: 001093, P/N: 4373381, Applied Biosystems) was used as internal control. Each sample was analyzed in triplicate.

Total RNA extraction and microarray profiling of miRNAs. Total RNA was isolated and purified from cell lines using miRNeasy Mini kit (Qiagen, Tokyo, Japan) as recommended by the manufacturer. RNA yield and quality was determined using the Agilent RNA 6000 Nano kit and Agilent 2100 Bioanalyzer (Agilent Technologies, Inc.). For all samples RNA integrity number (RIN) was $>7$.

Affymetrix GeneChip miRNA 4.0 array were used for miRNA profiling. Total RNA ( $1 \mu \mathrm{g}$ per sample) was labeled using the FlashTag ${ }^{\mathrm{TM}}$ Biotin HSR RNA Labeling kit (Affymetrix, Inc., USA) as described by the manufacturer. The samples were hybridized on GeneChip miRNA 4.0 arrays (Affymetrix, Inc.) for $18 \mathrm{~h}$ at $48^{\circ} \mathrm{C}$. Arrays were washed to remove non-specifically bound nucleic acids and stained on Fluidics Station 450 (Affymetrix, Inc.) and then scanned on GeneChip Scanner 3000 7G system (Affymetrix, Inc.). Finally, Microarray Data Analysis Tool version 3.2 (Filgen, Inc., Japan) was used as described in the manufacturer's instructions for all subsequent data analysis.

Statistical analysis. Data were analyzed with GraphPad Prism 5.0 (GraphPad Software, San Diego, CA, USA). To evaluate significant differences between two matched pair groups or between two independent groups of samples, paired $\mathrm{t}$-tests and non-paired t-tests were used, respectively. Pearson's correlation coefficient (r) was used to measure correlation, and logarithmic regression was used to calculate the R2 and to create the equation of the slope.

\section{Results}

Isolation of ALDHI high cells from HNSCC cell lines. ALDH1 activity is demonstrated to be a reliable marker for the isolation of cancer stem cells in several cancers including HNSCC (10). We analyzed ALDH activity by Aldefluor assay in two human HNSCC cell lines (UTSCC-9 and UTSCC-90). Cancer cells were sorted and isolated into two subpopulations as ALDH1 high (ALDH $\left.1^{\text {high }}\right)$ and low (ALDH1 ${ }^{\text {low }}$ ) by flow cytometry. Proportion of ALDH1 $1^{\text {high }}$ cells was found to be 12.3 and $10.3 \%$ for UTSCC-9 and UTSCC-90 cells, respectively (Fig. 1). These results were also confirmed by quantitative real-time PCR (qPCR) analysis. mRNA expression of ALDH1 was significantly higher in ALDH $1^{\text {high }}$ cells as compared to ALDH $1^{\text {low }}$ in both UTSCC-9 and UTSCC-90 cells (Fig. 2).

Characterization of $A L D H l^{\text {high }}$ cells. To analyze whether ALDH $1^{\text {high }}$ cells represent the CSC population of HNSCC, several characteristics related to stem cell were evaluated and 

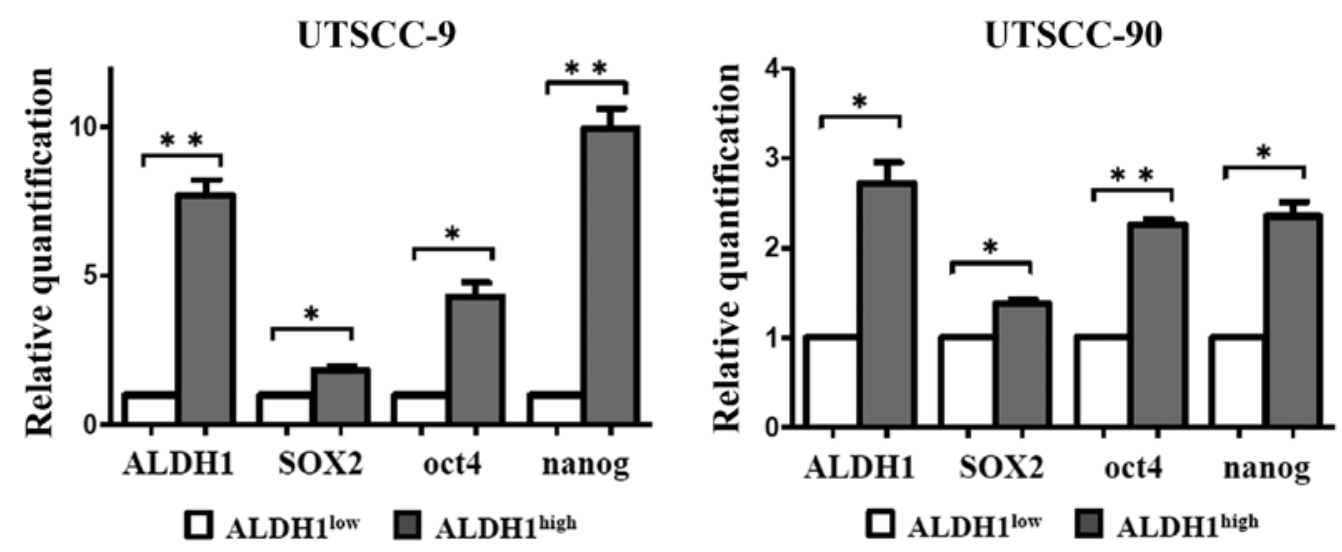

Figure 2. Expression of stem cell markers in ALDH1 $1^{\text {high }}$ and ALDH1 $1^{\text {low }}$ cells. mRNA purified from UTSCC-9 and UTSCC-90 cells were analyzed by real-time PCR. mRNA expression of stem cell markers including ALDH1, SOX2, Nanog and Oct 4 were compared between ALDH ${ }^{\text {low }}$ and ALDH ${ }^{\text {high }}$ cells. The horizontal bars represent the mean expression levels. Error bars represent $\mathrm{SD} ;{ }^{*} \mathrm{P}<0.05,{ }^{* *} \mathrm{P}<0.01$, by paired t-test.

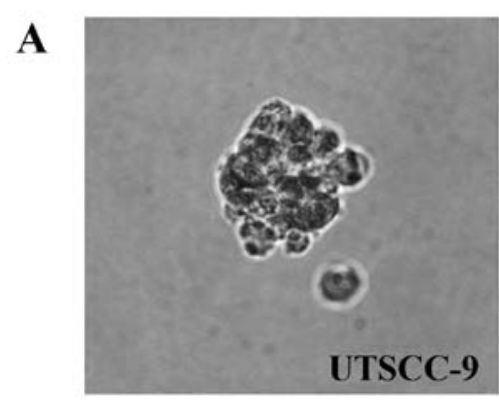

B

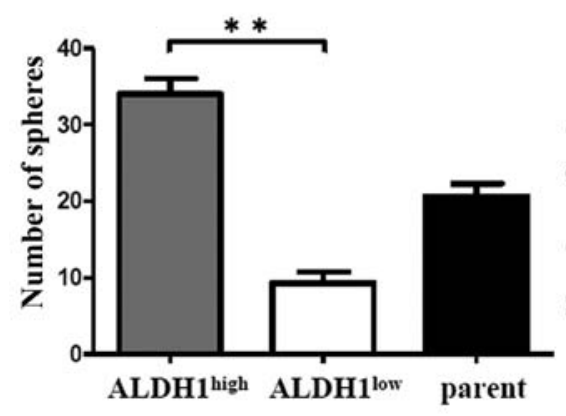

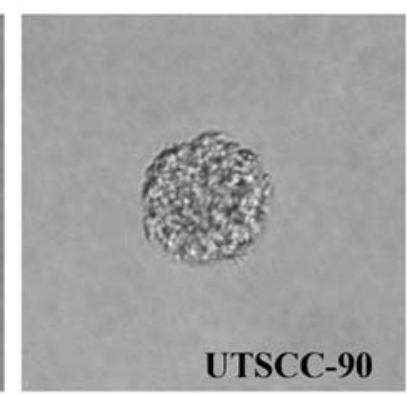

UTSCC-90

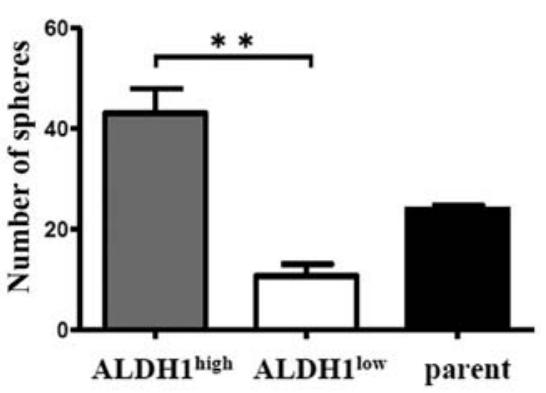

Figure 3. Sphere formation assay from UTSCC9 and UTSCC90. (A) Sphere formation of ALDH1 ${ }^{\text {high }}$ cells after cultivation in serum-free cell culture medium. (B) After ALDH1 $1^{\text {high }}, A L D H 1^{\text {low }}$ and parent $5 \times 10^{3}$ cells were cultured in 6 -well ultra-low attachment dishes, total number of spheres per well was counted. The horizontal bars represent the mean expression levels; ${ }^{*} \mathrm{P}<0.05,{ }^{* *} \mathrm{P}<0.01$, by unpaired t-test.

compared between ALDH1 $1^{\text {high }}$ and ALDH1 $1^{\text {low }}$ portions both for UTSCC-9 and UTSCC-90 cells.

First, the expression levels of stem cell markers including SOX2, Nanog and Oct4 were investigated by qPCR. The ALDH1 $1^{\text {high }}$ population of both HNSCC cell lines demonstrated increased expression levels of SOX2, Nanog and Oct4 as compared to ALDH1 $1^{\text {low }}$ cells with statistical significance (Fig. 2). The results were reproduced in three independent experiments. These results verified that ALDH1 ${ }^{\text {high }}$ cells derived from each cell line has similar genetic properties with CSCs.

CSCs are known to be able to grow in floating culture conditions as non-adherent, three-dimensional sphere clusters (spheres) (18). Therefore, sphere formation ability of
ALDH $1^{\text {high }}$ population was compared with ALDH1 $1^{\text {low }}$ and unsorted parent cells of UTSCC-9 and UTSCC-90. Sorted $5 \times 10^{3}$ cells per well were incubated into a 6-well plate in an anchorage-independent environment. The sphere formation assays were repeated in three independent experiments. Total number of spheres per well were counted after 28 days, and used to calculate the mean number of spheres.

ALDH $1^{\text {high }}$ cells derived from UTSCC-9 cells exhibited significantly increased sphere formation efficiency compared to ALDH1 ${ }^{\text {low }}$ cells $(\mathrm{P}<0.01)$. Similar results were obtained also for UTSCC-90 cells $(\mathrm{P}<0.01)$ (Fig. 3).

Increased tumorigenicity of $A L D H 1^{\text {high }}$ cells. To address the in vivo tumorigenicity of ALDH $1^{\text {high }}$ and $\mathrm{ALDH} 1^{\text {low }}$ cells, xeno- 

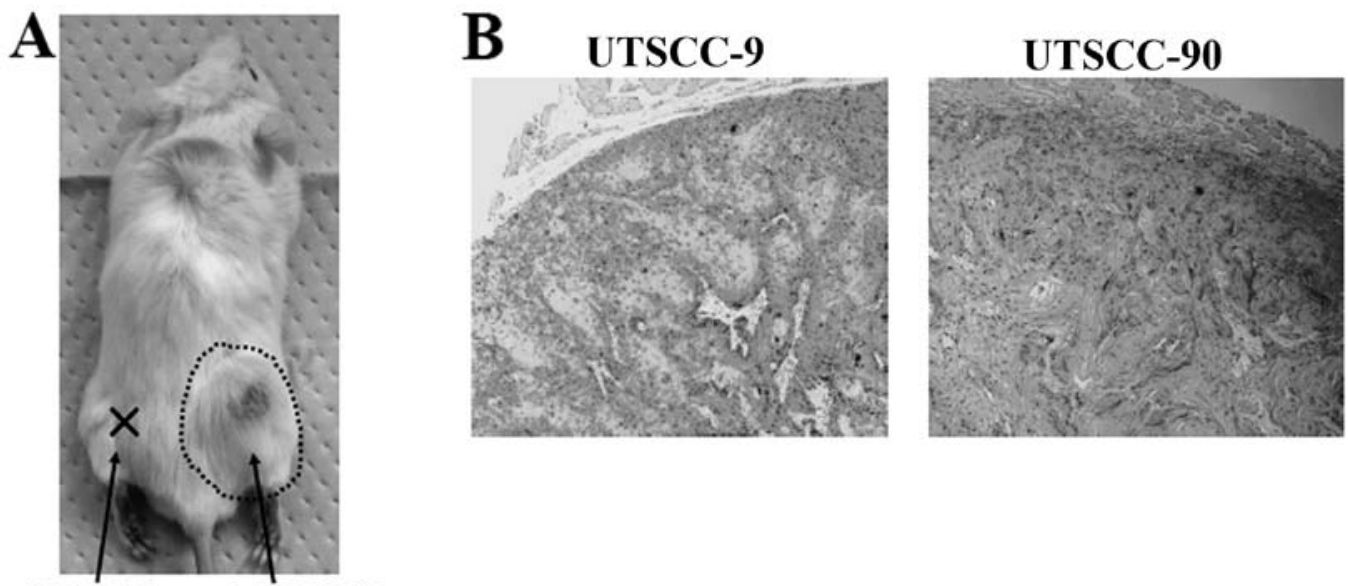

ALDH $^{\text {low }}$ ALDH $^{\text {high }}$
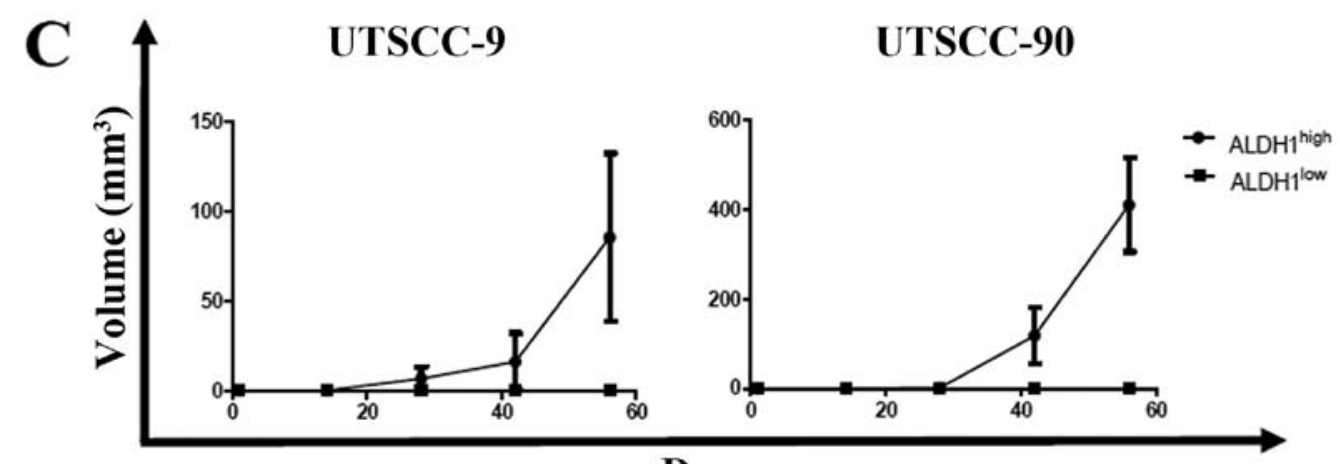

Days

Figure 4. Tumorigenicity of ALDH1 $1^{\text {high }}$ cells. (A) Representative tumor growth in NOD/SCID mice at the ALDH1 $1^{\text {high }}$ cell injection site (5x10 $0^{3}$ cells injected). $\mathrm{ALDH}^{1 \text { high }}$ and $\mathrm{ALDH} 1^{\text {low }}$ cells were inoculated subcutaneously into the left and right side of the back, respectively. (B) Histology images of ALDH1 ${ }^{\text {high }}$ tumors in mice (stained by hematoxylin and eosin). (C) Tumor growth in NOD/SCID mice by ALDH1 ${ }^{\text {high }}$ and ALDH1 ${ }^{\text {low }}$ subpopulations of UTSCC-9 and UTSCC-90 cells $\left(5 \times 10^{3}\right.$ cells injected). Data are reported as means \pm SD.

graft transplantation was performed into four NOD/SCID mice for each cell line group (UTSCC-9 and UTSCC-90). Sorted $5 \times 10^{3}$ cells from ALDH $1^{\text {high }}$ and ALDH $1^{\text {low }}$ cells were injected simultaneously into the subcutaneous region of right and left back sites for each NOD/SCID mice, respectively. One mouse in UTSCC-9 group died in the third week without any tumor detection. In UTSCC-90 group, ALDH $1^{\text {high }}$ cells produced tumors in all four mice, while ALDH $1^{\text {low }}$ cells did not produce any tumor. Similarly, tumor formation was observed in 2 of the 3 mice for ALDH $1^{\text {high }}$ cells, whereas no tumor occurred in sites injected with ALDH ${ }^{1 \text { low }}$ cells in UTSCC-9 group (Fig. 4A and C). The histology of tumors formed in NOD/SCID mice was verified to be squamous cell carcinoma (Fig. 4B). These results confirmed higher tumor-initiating ability of $\mathrm{ALDH} 1^{\text {high }}$ cells compared to ALDH1 ${ }^{\text {low }}$ cells in vivo.

MicroRNA expression profiles of ALDH $1^{\text {high }}$ vs ALDHI low cells. In order to characterize the miRNA expression profile that regulates genes involved in cancer stem cells of HNSCC, we performed a microarray analysis in UTSCC-9 and UTSCC-90 cells. Total RNA samples were prepared from ALDH $1^{\text {high }}$ vs ALDH $1^{\text {low }}$ subpopulations of each cell type. GeneChip miRNA 4.0 array (Affymetrix, Inc.) was used which contains 2,578 human mature miRNA probe sets annotated in the miRBase 20 database. One hybridization reaction was performed for each cell type.
By using stringent significance criteria of a $\geq 2$-fold difference in expression level and $\mathrm{P}<0.05$, we identified that nine miRNAs were differentially expressed between ALDH $1^{\text {high }}$ and ALDH1 ${ }^{\text {low }}$ subpopulations (Fig. 5). In ALDH $1^{\text {high }}$ cells, six out of nine miRNAs, including miR-424, let-7a, miR-4730, miR-6836, miR-6873, miR-7152 were significantly downregulated, while three miRNAs including miR-147b, miR-3622a-3p and miR-1976 were significantly upregulated.

Validation of microarray results by qPCR. To validate the microarray results, qPCR was performed with nine miRNAs that exhibited $>2$-fold change in expression. In agreement with the microarray results, expression of miR-424, let-7a, miR-6836, miR-6873 and miR-7152 were downregulated, whereas miR-147b was upregulated with statistical significance in the ALDH1 ${ }^{\text {high }}$ subpopulation (Fig. 6). Thus, the miRNA expression profiles of the cancer stem cells in HNSCC were confirmed by qPCR.

\section{Discussion}

In the present study, we found that the subpopulation of HNSCC cells with increased ALDH1 activity (ALDH $1^{\text {high }}$ ) represent cancer stem cells of HNSCC. Furthermore, we also revealed that ALDH1 $1^{\text {high }}$ HNSCC cells had a distinct microRNA expression profile as compared to ALDH1 ${ }^{\text {low }}$ cells. 


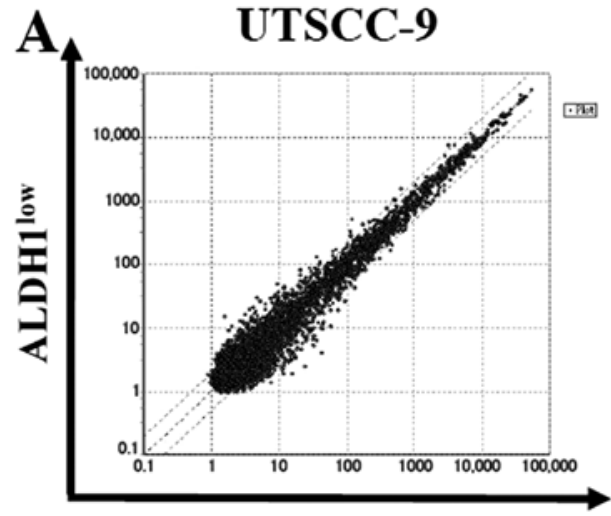

ALDH1 ${ }^{\text {high }}$

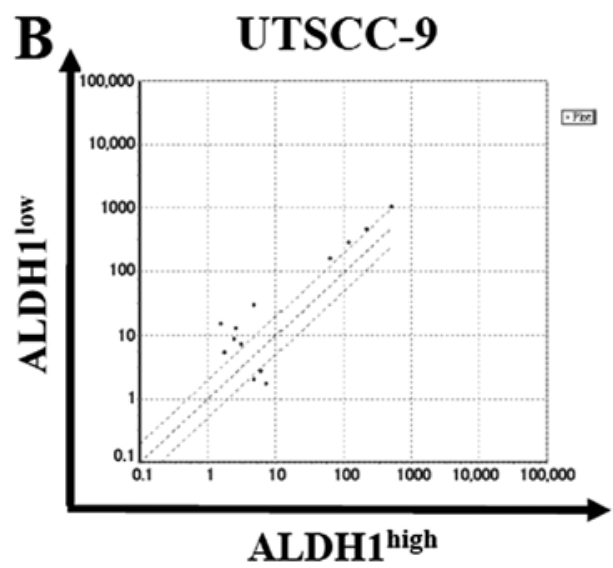

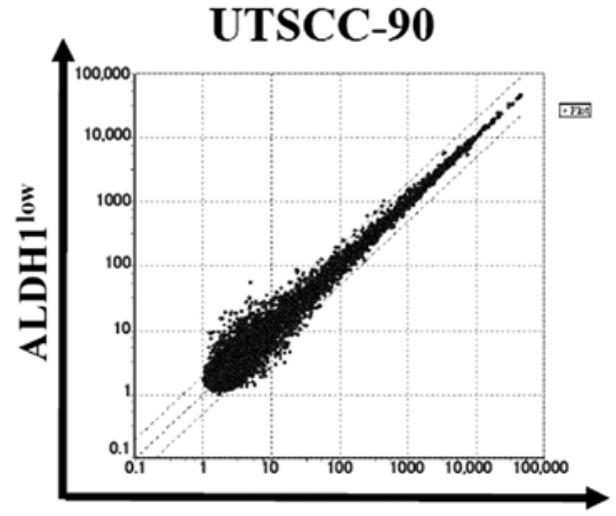

ALDH1 1ow

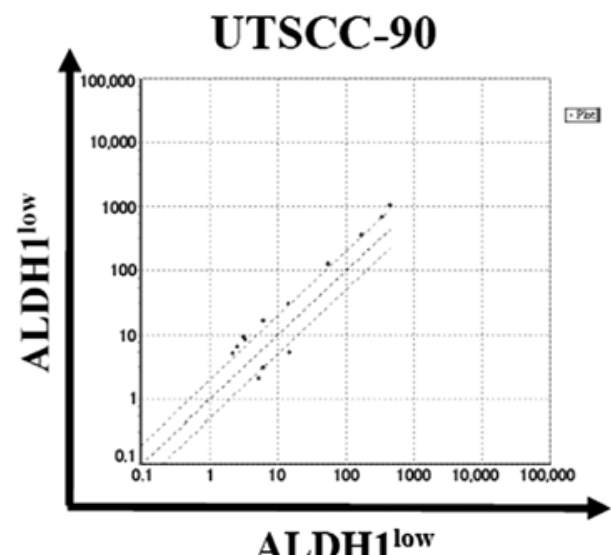

Figure 5. microRNA expression profiles in UTSCC-9 and UTSCC-90. (A) Scatter plot representation of whole mature miRNAs between ALDH1 $1^{\text {high }}$ (x-axis) vs $A L D H 1^{\text {low }}$ cells ( $y$-axis). (B) Scatter plot representation of differentially expressed miRNAs according to threshold of $\geq 2$-fold difference between ALDH $1^{\text {high }}$ (x-axis) vs ALDH1 ${ }^{\text {low }}$ cells (y-axis).
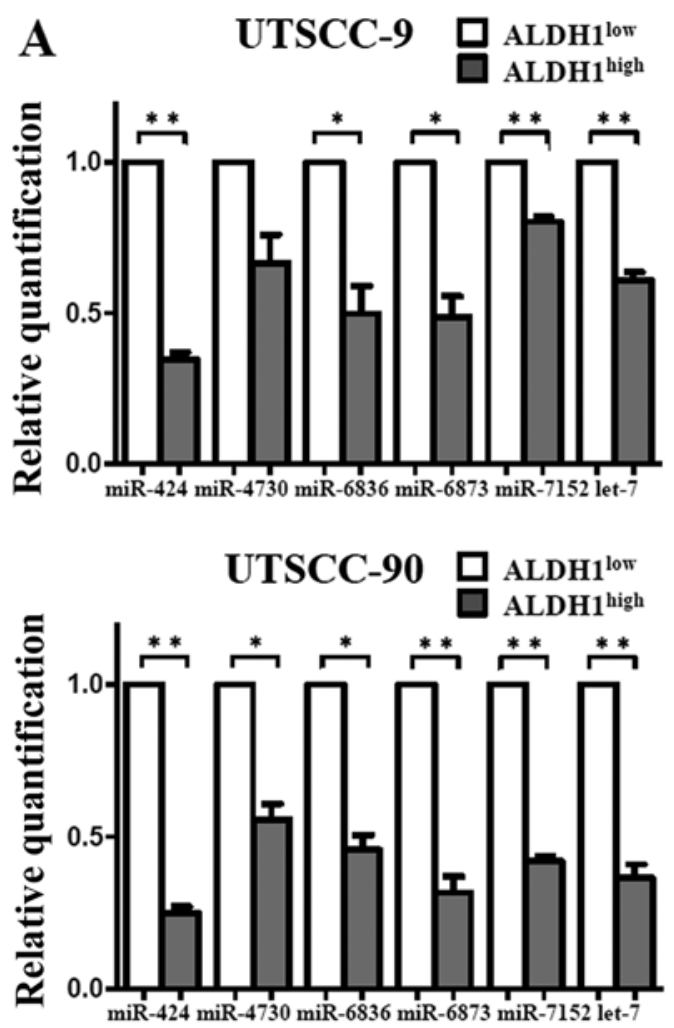
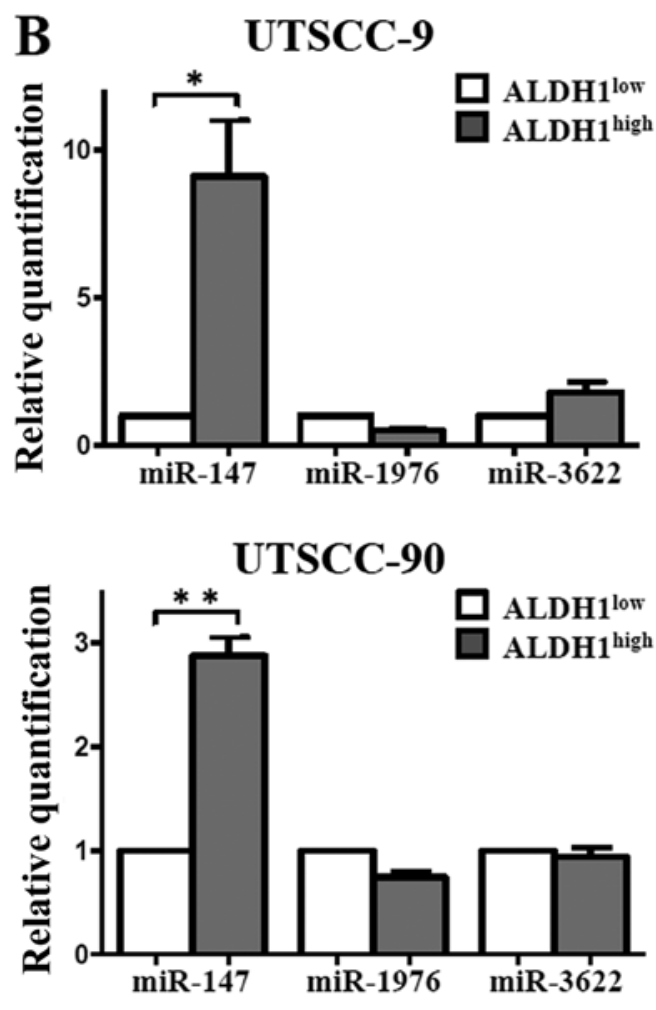

Figure 6. Real-time PCR analysis of microRNAs differentially expressed in microarray analysis. (A) Upregulated miRNAs in ALDH1 ${ }^{\text {high }}$ compared to ALDH1 ${ }^{\text {low }}$ cells: miR-424, let-7a, miR-4730, miR-6836, miR-6873 and miR-7152. (B) Downregulated miRNAs in ALDH1 ${ }^{\text {high }}$ compared to ALDH1 ${ }^{\text {low }}$ cells. The horizontal bars represent the mean expression levels; $\mathrm{P}<0.05,{ }^{* *} \mathrm{P}<0.01$, by paired $\mathrm{t}$-test. 
These findings might contribute to understanding miRNAdriven pathways related to the tumor-initiating capability of HNSCC.

Initially, we tested whether ALDH $1^{\text {high }}$ subpopulations of two HNSCC cell lines, UTSCC-9 and UTSCC-90, have cancer stemness properties. We isolated ALDH1 $1^{\text {high }}$ subpopulation by FACS and evaluated their stem cell features under in vitro and in vivo conditions. Results of our experiments including expression of stem cell markers (stemness-related genes), sphere formation capacity and xenograft transplantation into NOD/SCID mice supplied evidence that increased ALDH1 activity in HNSCC presents a subpopulation with high tumorinitiating ability.

Several types of approaches have been reported to isolate CSC fraction of cancer cells (19). CD44 is the first and most widely used cell surface biomarker to identify CSC in HNSCC (6). However, validity of CD44 has been questioned recently, since it is abundantly expressed in carcinoma cells and normal epithelium of head and neck region $(20,21)$. Furthermore, Clay et al proposed a new hypothesis on the relation of CD44 and ALDH1 with the cancer stem cell compartment in HNSCC. They suggest that ALDH-high subpopulation of HNSCC cells comprise only a minor fraction among the $\mathrm{CD} 44^{+}$cells, whereas more efficiently represent the CSC subpopulation itself (10). Recently, other reports also demonstrated ALDH1 expression as a reliable method to identify CSC in various epithelial cancers and HNSCC $(9,22)$. Our observations are consistent with previous data on the role of ALDH1 as a promising marker for identification of CSC.

Recently several studies have pointed out the essential role of miRNAs in regulation of CSCs in etiology and progression of various cancers including HNSCC (26-35). Total number of human mature microRNAs has increased remarkably from 1,105 to 2,578 according to the miRBase database in the last 5 years (14). However, only a limited number of studies have been reported on microRNA expression profiles of cancer stem cells in a few types of cancers $(23,24)$. Additionally, almost all of them were designed according to the previous and narrower version of probe entries. Accordingly, any miRNA signature has not been evaluated in HNSCC yet. Only one recent report, evaluated the relation of miRNAs with the radiosensitivity in laryngeal cancer stem cells represented by CD133+ forming subpopulations (25). They studied the alterations of miRNAs before and after radiotherapy exposure in only one cell line, whereas expression profile of miRNAs specific to cancer stem cell itself was not investigated.

In the next step, we evaluated microRNA expression profile of ALDH1 $1^{\text {high }}$ HNSCC cells. The results of microarray analysis in the cell lines of HNSCC showed that nine miRNAs were differentially expressed in ALDH $1^{\text {high }}$ HNSCC cells compared to ALDH1 ${ }^{\text {low }}$ cells. Among them, decreased expression of miR-424, let-7a, miR-4730, miR-6836, miR-6873, miR-7152 and overexpression of miR-147 were confirmed by qPCR assay, confirming the array results. This miRNA expression profile indicates stemness characteristics of HNSCC. Thus, miRNA regulation is intricately related to distinctive features and the biological performance of HNSCC cancer stem cells. By defining miRNAs related to the characteristics of HNSCC stem cells, we will be able to further clarify the regulatory pathway and gain insight into the features of these cancers.
Concerning miRNAs differentially expressed in our ALDH1 $1^{\text {high }}$ cells, there is no data currently in the literature on the function of four miRNAs (miR-4730, miR-6836, miR-6873 and miR-7152). This is due to the fact that these are novel miRNAs revealed by just the recent version of miRBase 20 (14). On the other hand, the role of miR-424, let-7a and miR-147 in carcinogenesis has been described by several studies.

miR-424 has been found to be downregulated in various type of cancers and it is proposed to act as a tumor suppressor in carcinogenesis $(26,27)$. Our data are the first on the expression status of miR-424 in HNSCC, while its downregulation was also observed in squamous cell carcinoma of the cervical region (28). miR-424 is predicted, by TargetScan, to target many mRNAs and recent studies have already validated important targets in cancer cells. miR-424 inhibits Weel and Chk1 related with chemo-resistance and radio-resistance in cancer cells (29). It also targets inhibitor of beta-catenin and TCF-4 (ICAT) and leads to inhibition of epithelial-mesenchymal transition (EMT) in hepatocellular carcinoma cells (30). Based on these findings, it is essential to clarify the role of miR-424 in regulation of CSC of HNSCC.

The let-7 family has been widely studied to have an essential function in stem cell differentiation and tumor-suppressive activity. Recently, let-7a was shown to negatively modulate the expression of stemness genes, and inhibit chemo-resistance and tumor initiating ability of ALDH1 (+) cell population in HNSCC (31). Our findings supported the tumor suppressive role of let-7a through cancer stem cells in HNSCC.

Profiling studies demonstrated that miR-147 was significantly overexpressed in gastric cancers and tongue cancers, consistent with our findings $(32,33)$, contrarily it was shown to be underexpressed in colon carcinomas (34). Interestingly, miR-147 was also found significantly associated with chemoresistance in small cell lung cancer (35).

The limitation of this study is the lack of functional studies to verify the potential role of those miRNAs differentially expressed in ALDH $1^{\text {high }}$ HNSCC cells. As a further step, designs of loss-of-function and gain-of-function experiments are required for each miRNA to evaluate their effect on cancer stem-like phenotypes such as drug resistance and cell invasion.

In conclusion, we validated cancer stem cell properties of ALDH1 $1^{\text {high }}$ subpopulation in HNSCC through in vivo and in vitro experiments. Furthermore, we identified a subset of miRNAs that were differentially expressed in ALDH $1^{\text {high }}$ subpopulation of HNSCC. These findings may provide new microRNA targets to study dysregulation of HNSCC-initiating cells and develop therapeutic strategies aimed at eradicating the tumorigenic subpopulation of cells in HNSCC. Thus, further investigation is required to validate the role of these microRNA candidates in HNSCC.

\section{Acknowledgements}

This study was supported in part by Doctorate Program Research Grant of Wakayama Medical University.

\section{References}

1. Dufour X, Beby-Defaux A, Agius G and Lacau St Guily J: HPV and head and neck cancer. Eur Ann Otorhinolaryngol Head Neck Dis 129: 26-31, 2012. 
2. Marur S and Forastiere AA: Head and neck cancer: Changing epidemiology, diagnosis, and treatment. Mayo Clin Proc 83: 489-501, 2008

3. Nguyen LV, Vanner R, Dirks P and Eaves CJ: Cancer stem cells: An evolving concept. Nat Rev Cancer 12: 133-143, 2012.

4. Bertolini G, Roz L, Perego P, Tortoreto M, Fontanella E, Gatti L, Pratesi G, Fabbri A, Andriani F, Tinelli S, et al: Highly tumorigenic lung cancer $\mathrm{CD}_{133^{+}}$cells display stem-like features and are spared by cisplatin treatment. Proc Natl Acad Sci USA 106: 16281-16286, 2009.

5. Baumann M, Krause M and Hill R: Exploring the role of cancer stem cells in radioresistance. Nat Rev Cancer 8: 545-554, 2008.

6. Prince ME, Sivanandan R, Kaczorowski A, Wolf GT, Kaplan MJ, Dalerba P, Weissman IL, Clarke MF and Ailles LE: Identification of a subpopulation of cells with cancer stem cell properties in head and neck squamous cell carcinoma. Proc Natl Acad Sci USA 104: 973-978, 2007.

7. O'Brien CA, Kreso A and Jamieson CH: Cancer stem cells and self-renewal. Clin Cancer Res 16: 3113-3120, 2010.

8. Ginestier C, Hur MH, Charafe-Jauffret E, Monville F, Dutcher J, Brown M, Jacquemier J, Viens P, Kleer CG, Liu S, et al: ALDH1 is a marker of normal and malignant human mammary stem cells and a predictor of poor clinical outcome. Cell Stem Cell 1: 555-567, 2007.

9. Chen YC, Chen YW, Hsu HS, Tseng LM, Huang PI, Lu KH, Chen DT, Tai LK, Yung MC, Chang SC, et al: Aldehyde dehydrogenase 1 is a putative marker for cancer stem cells in head and neck squamous cancer. Biochem Biophys Res Commun 385: 307-313, 2009

10. Clay MR, Tabor M, Owen JH, Carey TE, Bradford CR, Wolf GT, Wicha MS and Prince ME: Single-marker identification of head and neck squamous cell carcinoma cancer stem cells with aldehyde dehydrogenase. Head Neck 32: 1195-1201, 2010.

11. Shcherbata HR, Hatfield S, Ward EJ, Reynolds S, Fischer KA and Ruohola-Baker H: The MicroRNA pathway plays a regulatory role in stem cell division. Cell Cycle 5: 172-175, 2006.

12. Tamagawa S, Beder LB, Hotomi M, Gunduz M, Yata K, Grenman R and Yamanaka N: Role of miR-200c/miR-141 in the regulation of epithelial-mesenchymal transition and migration in head and neck squamous cell carcinoma. Int J Mol Med 33: 879-886, 2014

13. DeSano JT and Xu L: MicroRNA regulation of cancer stem cells and therapeutic implications. AAPS J 11: 682-692, 2009.

14. Kozomara A and Griffiths-Jones S: miRBase: Annotating high confidence microRNAs using deep sequencing data. Nucleic Acids Res 42 (D1): D68-D73, 2014.

15. Minn H, Clavo AC, Grénman R and Wahl RL: In vitro comparison of cell proliferation kinetics and uptake of tritiated fluorodeoxyglucose and L-methionine in squamous-cell carcinoma of the head and neck. J Nucl Med 36: 252-258, 1995.

16. Lansford CD, Grenman R, Bier H, Somers KD, Kim S-Y, Whiteside TL, Clayman GL, Welkoborsky H-J and Carey TE: Head and neck cancers. In: Human Cell Culture, Vol. 2, Cancer Cell Lines Part 2. Masters JR and Palsson B (eds). Norwell: Kluwer Academic Publishers, pp185-255, 1999.

17. Livak KJ and Schmittgen TD: Analysis of relative gene expression data using real-time quantitative PCR and the 2 (-Delta Delta C (T)) method. Methods 25: 402-408, 2001.

18. Pastrana E, Silva-Vargas V and Doetsch F: Eyes wide open: A critical review of sphere-formation as an assay for stem cells. Cell Stem Cell 8: 486-498, 2011.

19. Major AG, Pitty LP and Farah CS: Cancer stem cell markers in head and neck squamous cell carcinoma. Stem Cells Int 2013 319489, 2013.
20. Chen C, Wei Y, Hummel M, Hoffmann TK, Gross M, Kaufmann AM and Albers AE: Evidence for epithelialmesenchymal transition in cancer stem cells of head and neck squamous cell carcinoma. PLoS One 6: e16466, 2011.

21. Mack B and Gires O: CD44s and CD44v6 expression in head and neck epithelia. PLoS One 3: e3360, 2008.

22. Deng S, Yang X, Lassus H, Liang S, Kaur S, Ye Q, Li C, Wang LP, Roby KF, Orsulic S, et al: Distinct expression levels and patterns of stem cell marker, aldehyde dehydrogenase isoform 1 (ALDH1), in human epithelial cancers. PLoS One 5: e10277, 2010.

23. Nam EJ, Lee M, Yim GW, Kim JH, Kim S, Kim SW and Kim YT: MicroRNA profiling of a CD133 (+) spheroid-forming subpopulation of the OVCAR3 human ovarian cancer cell line. BMC Med Genomics 5: 18, 2012.

24. Sun JG, Liao RX, Qiu J, Jin JY, Wang XX, Duan YZ, Chen FL, Hao P, Xie QC, Wang ZX, et al: Microarray-based analysis of microRNA expression in breast cancer stem cells. J Exp Clin Cancer Res 29: 174, 2010.

25. Huang CX, Zhu Y, Duan GL, Yao JF, Li ZY, Li D and Wang QQ: Screening for MiRNAs related to laryngeal squamous carcinoma stem cell radiation. Asian Pac J Cancer Prev 14: 4533-4537, 2013.

26. Oneyama C, Kito Y, Asai R, Ikeda J, Yoshida T, Okuzaki D, Kokuda R, Kakumoto K, Takayama K, Inoue S, et al: MiR-424/503-mediated Rictor upregulation promotes tumor progression. PLoS One 8: e80300, 2013.

27. Xu J, Li Y, Wang F, Wang X, Cheng B, Ye F, Xie X, Zhou C and Lu W: Suppressed miR-424 expression via upregulation of target gene Chk1 contributes to the progression of cervical cancer. Oncogene 32: 976-987, 2013

28. Cheung TH, Man KN, Yu MY, Yim SF, Siu NS, Lo KW, Doran G, Wong RR, Wang VW, Smith DI, et al: Dysregulated microRNAs in the pathogenesis and progression of cervical neoplasm. Cell Cycle 11: 2876-2884, 2012.

29. Pouliot LM, Chen YC, Bai J, Guha R, Martin SE, Gottesman MM and Hall MD: Cisplatin sensitivity mediated by WEE1 and CHK1 is mediated by miR-155 and the miR-15 family. Cancer Res 72: 5945-5955, 2012.

30. Zhang Y, Li T, Guo P, Kang J, Wei Q, Jia X, Zhao W, Huai W, Qiu Y, Sun L, et al: MiR-424-5p reversed epithelial-mesenchymal transition of anchorage-independent HCC cells by directly targeting ICAT and suppressed HCC progression. Sci Rep 4: 6248,2014

31. Yu CC, Chen YW, Chiou GY, Tsai LL, Huang PI, Chang CY, Tseng LM, Chiou SH, Yen SH, Chou MY, et al: MicroRNA let-7a represses chemoresistance and tumourigenicity in head and neck cancer via stem-like properties ablation. Oral Oncol 47: 202-210, 2011.

32. Yao Y, Suo AL, Li ZF, Liu LY, Tian T, Ni L, Zhang WG, Nan KJ, Song TS and Huang C: MicroRNA profiling of human gastric cancer. Mol Med Rep 2: 963-970, 2009.

33. Wong TS, Liu XB, Wong BY, Ng RW, Yuen AP and Wei WI: Mature miR-184 as potential oncogenic microRNA of squamous cell carcinoma of tongue. Clin Cancer Res 14: 2588-2592, 2008.

34. Gaedcke J, Grade M, Camps J, Søkilde R, Kaczkowski B, Schetter AJ, Difilippantonio MJ, Harris CC, Ghadimi BM, Møller S, et al: The rectal cancer microRNAome - microRNA expression in rectal cancer and matched normal mucosa. Clin Cancer Res 18: 4919-4930, 2012.

35. Ranade AR, Cherba D, Sridhar S, Richardson P, Webb C, Paripati A, Bowles B and Weiss GJ: MicroRNA 92a-2*: A biomarker predictive for chemoresistance and prognostic for survival in patients with small cell lung cancer. J Thorac Oncol 5: 1273-1278, 2010. 